\title{
Direct Load Control (DLC) Considering Nodal Interrupted Energy Assessment Rate (NIEAR) in Restructured Power Systems
}

\author{
Wu, Qiuwei; Wang, Peng; Goel, Lalit
}

Published in:

IEEE Transactions on Power Systems

Link to article, DOI:

10.1109/TPWRS.2009.2038920

Publication date:

2010

Document Version

Publisher's PDF, also known as Version of record

Link back to DTU Orbit

Citation (APA):

Wu, Q., Wang, P., \& Goel, L. (2010). Direct Load Control (DLC) Considering Nodal Interrupted Energy Assessment Rate (NIEAR) in Restructured Power Systems. IEEE Transactions on Power Systems, 25(3), 14491456. https://doi.org/10.1109/TPWRS.2009.2038920

\section{General rights}

Copyright and moral rights for the publications made accessible in the public portal are retained by the authors and/or other copyright owners and it is a condition of accessing publications that users recognise and abide by the legal requirements associated with these rights.

- Users may download and print one copy of any publication from the public portal for the purpose of private study or research.

- You may not further distribute the material or use it for any profit-making activity or commercial gain

- You may freely distribute the URL identifying the publication in the public portal 


\title{
Direct Load Control (DLC) Considering Nodal Interrupted Energy Assessment Rate (NIEAR) in Restructured Power Systems
}

\author{
Qiuwei Wu, Member, IEEE, Peng Wang, Member, IEEE, and Lalit Goel, Senior Member, IEEE
}

\begin{abstract}
A direct load control (DLC) scheme of air conditioning loads (ACL) considering direct monetary compensation to ACL customers for the service interruption caused by the DLC program is proposed in this paper for restructured power systems. The nodal interrupted energy assessment rate (NIEAR), which is used as the bids from the ACL customers, is utilized to determine the direct monetary compensation to the ACL customers. The proposed scheme was investigated for the PoolCo electricity market. The optimal DLC scheme is determined based on the minimum system operating cost which is comprised of the system energy cost, the system spinning reserve cost and the compensation cost to the ACL customers. Dynamic programming (DP) was used to obtain the optimal DLC scheme. The IEEE reliability test system (RTS) was studied to illustrate the proposed DLC scheme.
\end{abstract}

Index Terms-Air conditioning loads, direct load control, dynamic programming, nodal interrupted energy assessment rate, reliability test system (RTS), restructured power systems.

\section{INTRODUCTION}

C URRENTLY power systems in many countries are operated under the competitive environment. The historic monopoly regulated power systems have largely been replaced by restructured power systems. The purposes of restructuring are to introduce competition among electricity suppliers and to provide consumers more choices in terms of suppliers and economic benefits [1]-[4]. However, the restructuring of power systems has also been accompanied by a number of problems including capacity shortage, transmission congestion, wholesale price volatility, and possible reduced system reliability. Load management has accordingly emerged as an important element of the fine-tuning of the operation of restructured power systems [5].

The direct load control (DLC) of air conditioning loads (ACL) is a common load management program to shape the load curve in order to increase the system reliability and to reduce the system operating cost by cycling the ACL. Intensive

Manuscript received July 13, 2009; revised October 31, 2009. First published January 26, 2010; current version published July 21, 2010. Paper no. TPWRS00540-2009.

Q. Wu is with the Center for Electric Technology, Technical University of Denmark, DK-2800 Kgs. Lyngby, Denmark (e-mail: wuqi0001@ntu.edu.sg; qw@elektro.dtu.dk).

P. Wang and L. Goel are with the School of Electrical and Electronic Engineering, Nanyang Technological University, Singapore 639798, Singapore.

Color versions of one or more of the figures in this paper are available online at http://ieeexplore.ieee.org.

Digital Object Identifier 10.1109/TPWRS.2009.2038920 studies have been done on the DLC technique. An effective optimization method for scheduling load management was developed based on an analytical model of the load under control which allowed any length for the control periods and any cycle rates [6]. The impact of dynamic dispatch of DLC on generation system reliability performance was studied using the Monte Carlo simulation methodology [7]. Duty Cycle Model and the Demand-Side Design and Analysis Workstation were described in [8]. The dynamic DLC model is coupled with a fast piece-wise linear incremental cost economic dispatch scheme to study the production cost implications [9]. An effective optimization method for scheduling DLC in the commercial buildings was presented to minimize the load reduction so as to lessen the effects of customers' discomfort and to maintain the Taiwan Power Company's total incomes [10]. A fuzzy load model for the direct load control of appliances was first developed and a methodology for optimizing both customer satisfaction and utility unit commitment savings was presented based on this fuzzy DLC load model [11]. A DLC program controlled by local bus frequency was proposed for damping of electro-mechanical oscillations [12] and the proposed DLC program was studied by carrying out the case study of one load in a three-machine system with a meshed network. Physically based electrical models of heating, ventilation and air conditioning residential loads were proposed [13] and the proposed models were implemented and tested to assess their accuracy and suitability in specific kinds of applications. An approach was proposed to determine a boundary of small-signal stability performance of a power system in terms of active power loads selected at a few buses [14]. The framework of preventive modulation of selected loads through direct control for small-disturbance angle stability enhancement was presented [15] and the results on an equivalent of the Western Electric Coordinating Council (WECC) system were presented [16]. An interactive evolutionary algorithm for the identification and selection of DLC actions in electrical distribution networks was proposed in [17].

The resultant service interruption of the DLC of ACL causes discomfort to the customers due to the short-term temperature increase. Traditionally, the customers who participated in the DLC program have received an incentive rate which is the same for all the customers. Rewarding all customers equally for participating in the DLC program may over-compensate some customers and under-compensate others. In a power system which operates as a market, the operation is decentralized. In the power market, a customer may have a choice on his reliability and may 
want to pay a higher price for a more reliable supply or pay less for lower reliability. The customers who are willing to pay more for their reliability will get more compensation. The interruption cost which shows a customer willingness to pay for more (or less) reliability should be considered in the scheme. On the other hand, customers connected to different nodes of a power system may also have different reliabilities and electricity prices due to the network constraints. The same load change at different nodes will have different effects on the system reliability. It is therefore important to design the compensation scheme considering all these issues in the new operating environment.

In this paper, a novel compensation scheme is proposed based on the nodal interrupted energy assessment rate (NIEAR) which considers both nodal reliability and customer willingness to pay for his reliability to encourage the ACL customers to participate in the DLC program. In the scheme, the NIEAR is treated as the bids from the ACL customers. In a time period of the DLC, if a customer agrees to disconnect its ACL, the compensation is determined using the NIEAR. Dynamic programming (DP) is used to determine the optimal DLC scheme with the minimum overall system operating cost.

The arrangement of the paper is as follows. The PoolCo electricity market comprising both the energy market and the spinning reserve market is presented in Section II. The determination of the NIEAR is presented in Section III. In Section IV, the formulation of the optimal DLC scheme considering the NIEAR is depicted. In Section V, the IEEE RTS [18] is used to illustrate the proposed DLC scheme. The impacts of the proposed DCL scheme on the system operating cost reduction and the system reliability improvement were investigated, and the corresponding compensations to different customers are also presented.

\section{ENERGY MARKET AND SPINNING RESERVE MARKET}

The PoolCo electricity market comprising the energy market and the spinning reserve market is used as the framework to implement the study of the proposed DLC scheme.

In the PoolCo energy market, the electricity price is determined by the demands and the offers from generation companies considering the system constraints. Nodal prices which are the calculated shadow prices are used. The nodal prices for each time period are determined separately by solving the following optimization problem.

Objective Function:

$$
\operatorname{Min} \sum_{i=1}^{N_{g}}\left(a \times\left(P_{g i}\right)^{2}+b \times P_{g i}+c\right)
$$

subject to the following constraints:

Power balance constraints:

$$
\begin{aligned}
& \sum_{i \in j} P_{g i}-d_{p j}-\sum_{k \in j} V_{j} V_{k} Y_{j k} \cos \left(\theta_{j k}+\delta_{j}-\delta_{k}\right)=0 \\
& \sum_{i \in j} Q_{g i}-d_{q j}-\sum_{k \in j} V_{j} V_{k} Y_{j k} \sin \left(\theta_{j k}+\delta_{j}-\delta_{k}\right)=0 .
\end{aligned}
$$

Generation unit constraints:

$$
\begin{aligned}
P_{g i}^{\min } & \leq P_{g i} \leq P_{g i}^{\max } \\
Q_{g i}^{\max } & \leq Q_{g i} \leq Q_{g i}^{\max }
\end{aligned}
$$

Voltage constraints:

$$
V_{j}^{\min } \leq V_{j} \leq V_{j}^{\max } .
$$

Transmission line flow constraints:

$$
P_{l i}^{\min } \leq P_{l i} \leq P_{l i}^{\max }
$$

where $P_{g i}$ and $Q_{g i}$ are the real and reactive power output of generator $i$, respectively; $d_{p j}$ and $d_{q j}$ are the real and reactive power demand at node $j$, respectively; $P_{g i}^{\min }$ and $P_{g i}^{\max }$ are the minimum and maximum real power output of generator $i$, respectively; $Q_{g i}^{\min }$ and $Q_{g i}^{\max }$ are the minimum and maximum reactive power output of generator $i$, respectively; $V_{j}^{\min }$ and $V_{j}^{\max }$ are the minimum and maximum voltage at node $j$, respectively; $P_{l i}^{\min }$ and $P_{l i}^{\max }$ are the minimum and maximum real power flow allowed through transmission line $i$, respectively; $V_{j} \angle \delta_{j}$ is the voltages at nodes $j$; and $Y_{j k} \angle \theta_{j k}$ is the admittance between nodes $j$ and $k$.

Lagrange function of (1)-(7) is given in (8):

$$
\begin{aligned}
& L=\sum_{i=1}^{N_{g}}\left(C_{P i}\left(P_{g i}\right)+C_{q i}\left(Q_{g i}\right)\right) \\
& +\sum_{j=1}^{N_{n}} \lambda_{p j}\left(\sum_{i \in j} P_{g i}-P_{d j}\right. \\
& \left.-\sum_{k \in j} V_{j} V_{k} Y_{k j} \cos \left(\theta_{j k}+\delta_{j}-\delta_{k}\right)\right) \\
& +\sum_{j=1}^{N_{n}} \lambda_{q j}\left(\sum_{i \in j} Q_{g i}-Q_{d j}\right. \\
& \left.-\sum_{k \in j} V_{j} V_{k} Y_{k j} \sin \left(\theta_{j k}+\delta_{j}-\delta_{k}\right)\right) \\
& +\sum_{i=1}^{N_{g}} u_{p i \min }\left(P_{g i \min }-P_{g i}\right) \\
& +\sum_{i=1}^{N_{g}} u_{p i \max }\left(P_{g i}-P_{g i \max }\right) \\
& +\sum_{i=1}^{N_{g}} u_{q i \min }\left(Q_{g i \min }-Q_{g i}\right) \\
& +\sum_{i=1}^{N_{l}} u_{\lim i n}\left(P_{\lim i n}-P_{l i}\right) \\
& +\sum_{i=1}^{N_{l}} u_{\lim a x}\left(P_{l i}-P_{\lim a x}\right) \\
& +\sum_{j=1}^{N_{n}} u_{v j \min }\left(V_{j \min }-V_{j}\right) \\
& +\sum_{j=1}^{N_{n}} u_{v j \max }\left(V_{j}-V_{v j \max }\right)
\end{aligned}
$$


where $N_{l}$ is the number of power lines, $N_{n}$ is the number of nodes, and $\lambda_{p j}, \lambda_{q j}, \mu_{p i \min }, \mu_{p i \max }, \mu_{q i \min }, \mu_{q i \max }, \mu_{\text {limin }}$, $\mu_{\lim a x}, u_{v j \min }$ and $u_{v j \max }$ are the Lagrangian multipliers of the corresponding constraints.

The nodal prices of real and reactive powers at node $j$ are the shadow prices at the optimal solution condition of (8) and are given by (9) and (10):

$$
\begin{gathered}
\rho_{p j}=\frac{\partial L}{\partial P_{d j}} \\
\rho_{q j}=\frac{\partial L}{\partial Q_{d j}} .
\end{gathered}
$$

Spinning reserve (SR) is the amount of generation made available to restore the system operation immediately after an outage event. The ISO evaluates the SR requirements for the system on a day to day and hour to hour basis to ensure that SR is available when required. The ISO can procure this service from the synchronized generation units that are able to respond within about $10 \mathrm{~min}$ from the request while satisfying their ramp rates.

In this paper, a competitive SR market is utilized to determine the SR price which is a uniform market price of SR derived from a competitive auction model. A generator participating in the SR market provides the ISO with a quantity of SR in MW and a bid price in $\$ / M W$, which indicates its price expectation per unit real power deviation from its scheduled operating point. Once the ISO receives all the bids, the uniform SR price $\rho$ for SR can be determined. The objective is to minimize the overall SR cost. The determination of SR price is presented as the optimization problem below.

Objective Function:

$$
\min \left(\sum_{i=1}^{N_{g}} P_{S R i} \times \rho\right)
$$

subject to the following constraints:

SR requirement constraint:

$$
\sum_{i=1}^{N_{g}} P_{S R i} \geq S R R .
$$

Generator SR constraint:

$$
0 \leq P_{S R i} \leq S R L_{i}
$$

Price constraint:

$$
\rho \geq \beta_{i} \times W_{i}
$$

where $P_{S R i}$ is the SR provided by generator $i, S R R$ is the system SR requirement, $S R L_{i}$ is the biddable SR limit of generator $i, \beta_{i}$ is the SR bid price of generator $i$, and $W_{i}$ is an integer variable to denote the selection state of a particular bid from generator $i$.

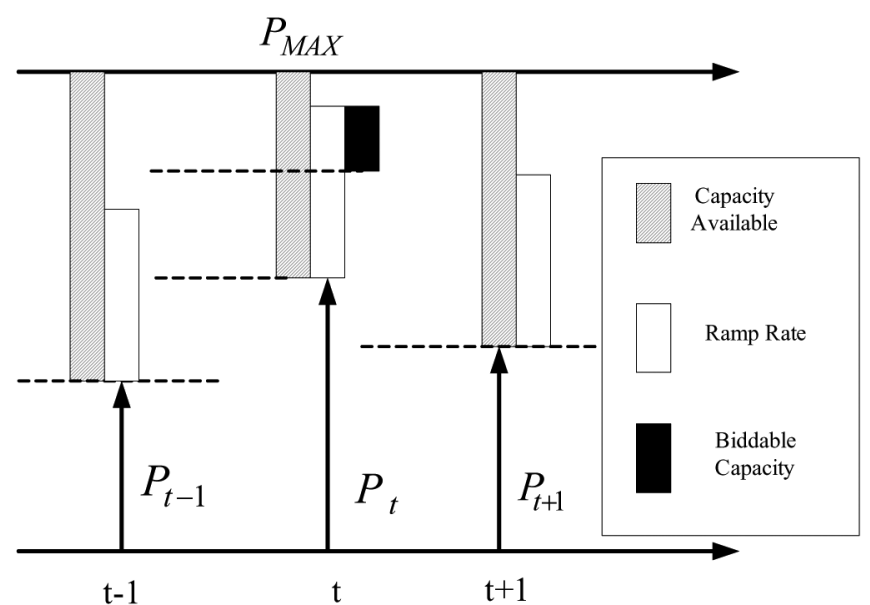

Fig. 1. SR limit of a generator.

The biddable SR limit for generator $i$ can be obtained using (15) $[4]:$

$$
\begin{aligned}
S R L_{i}=\min \left\{\operatorname { m i n } \left\{R A M P_{i}\right.\right. & ,\left(R A M P_{i}\right. \\
& \left.\left.\left.-\left(P_{t}-P_{t-1}\right)\right)\right\}, \mathrm{CAP}_{i}\right\}
\end{aligned}
$$

where $R A M P_{i}$ is the ramp rate of generator $i, P_{t}$ and $P_{t-1}$ are real power output of generator $i$ at time $t$ and $t-1, C A P_{i}$ is the capacity available of generator $i$ and is the difference between the maximum and actual real power outputs. Fig. 1 shows the dynamic determination of SR limit of a generator at any time period.

As described in (15), in order to determine the biddable SR capacity for period $t$ the first step is to find the smaller quantity between the ramp rate and the ramp rate minus $\left(P_{t}-P_{t-1}\right)$. The minimum value from the smaller and the available capacity is the biddable capacity.

If the generation difference between time period $t$ and time period $t-1$ is positive, the biddable SR capacity will be reduced. The available capacity is the difference between the maximum generation output and the actual generation output in time pe$\operatorname{riod} t$. The available capacity of the generator is another limit for the biddable SR capacity. As illustrated in Fig. 1, the biddable SR capacity is the black block.

\section{DETERMINATION OF NIEAR}

The IEAR is a system reliability index which relates system customer energy losses caused by electric power interruptions to the worth of the system reliability through customer interruption costs. A generic method for calculating the IEAR was presented in [19] and both the frequency and duration approach and the Monte Carlo simulation approach were used to calculate the IEAR. In [20], the method of calculating the IEAR was extended to composite power systems. In [21] and [22], the IEAR assessment method in [19] was extended to assess the IEAR of distribution systems and overall power systems. The system IEAR is defined as the ratio between the expected customer interruption cost and the expected energy not supplied. 
Nodal IEAR is defined in this paper to relate the nodal energy losses to the worth of nodal reliability in order to determine the compensations to different customers. The NIEAR is calculated using the nodal expected customer interruption cost and the nodal expected energy not supplied. The NIEAR can be determined by using contingency enumeration reliability techniques. The details of the calculation of the NIEAR are presented below.

Considering an $n$-bus power system with $m$ independent components, for contingency state $j$ with exactly $s$ failed components, the state probability $p_{j}$, the state departure rate $D_{j}$, the frequency of the system departing from the state $F_{j}$, and state duration $d_{j}$ are given in (16)-(19):

$$
\begin{aligned}
p_{j} & =\prod_{i=1}^{s} U_{i} \times \prod_{i=s+1}^{m} A_{i} \\
D_{j} & =\sum_{i=1}^{s} \mu_{i}+\sum_{i=s+1}^{m} \lambda_{i} \\
F_{j} & =p_{j} \times D_{j} \\
d_{j} & =\frac{1}{D_{j}}
\end{aligned}
$$

where $A_{i}, U_{i}, \lambda_{i}$, and $\mu_{i}$ are the availability, unavailability, failure rate, and repair rate of component $i$, respectively.

The expected energy not served at node $k, E E N S_{k}$, is given in (20):

$$
E E N S_{k}=\sum_{j=1}^{N C} L C_{k j} F_{j} d_{j}
$$

where $L C_{k j}$ is the load curtailment at node $k$ under contingency $j$, NC is the total number of the considered contingencies.

The expected customer interruption cost at node $k, E C O S T_{k}$ is given in (21):

$$
\operatorname{ECOST}_{k}=\sum_{j=1}^{k} L C_{k j} F_{j} C_{k}\left(d_{j}\right)
$$

where $C_{k}\left(d_{j}\right)$ is the customer cost for interruption duration $d_{j}$ at node $k$ under contingency $j$ which can be obtained from the customer damage functions (CDF) at node $k$.

The CDF has been developed to evaluate the customer losses due to the electric service interruptions which is a cost estimate associated with power supply interruption duration and customer sectors [23], [24]. In this paper, all the customers are assumed to be ACL customers and the corresponding CDF [23], [24] is used.

The NIEAR at node $k$ can be calculated by (22):

$$
N I E A R_{k}=\frac{\sum_{j=1}^{N C} L C_{k j} F_{j} C_{k}\left(d_{j}\right)}{\sum_{j=1}^{N C} L C_{k j} F_{j} d_{j}} .
$$

\section{DLC Formulation AND SOlUtion ALGORITHM}

The objective of the DLC is to schedule the cycling on/off times and durations of ACL customers at different nodes based on their interruption costs, aiming to reduce the peak load. In restructured power systems, the power price is high when the demand is high. Therefore, the objective of the DLC can be interpreted as reducing the overall system operating cost as much as possible.

The objective of the proposed DLC is to minimize the overall system operating cost comprising the energy cost, the spinning reserve cost and the compensation to the ACL customers. The formulation of the DLC problem considering the NIEAR is presented in the dynamic recursive form below.

At the $n$th stage of the DLC, the objective is to minimize the cumulated system operating cost of the $j$ th state:

$$
\begin{aligned}
C(n, j)=\min _{\{m\}}( & \operatorname{Min} \sum_{i=1}^{N_{g}}\left(a \times\left(P_{g i}(n, j)\right)^{2}\right. \\
& \left.+b \times P_{g i}(n, j)+c\right) \\
& +\min \left(\sum_{i=1}^{N_{g}} P_{S R i}(n, j) \times \rho(n, j)\right) \\
& +\sum_{i=1}^{N_{A C L}}\left(u_{i}(n, j) \times N I E A R_{i} \times L_{i A C L}\right) \\
& +C(n-1, m))
\end{aligned}
$$

where $N_{A C L}$ is the number of the ACL groups, $\mu_{(n, j)}$ is the state of the $i$ th group, NIEAR is the NIEAR of the $i$ th group connects, $L_{i A C L}$ is the load of the $i$ th group, $\{m\}$ is the selected set of feasible states at the $(n-1)$ th stage, subject to the following constraints:

Power flow constraints:

$$
\begin{aligned}
& \sum_{i \in k} P_{g i}(n, j)-P_{d k}^{\prime}(n, j) \\
& \quad-\sum_{l \in k} V_{k}(n, j) V_{l}(n, j) Y_{k l} \cos \left(\theta_{k l}+\delta_{k}(n, j)-\delta_{l}(n, j)\right) \\
& \quad=0 \\
& \sum_{i \in k} Q_{g i}(n, j)-Q_{d k}^{\prime}(n, j) \\
& \quad-\sum_{l \in k} V_{k}(n, j) V_{l}(n, j) Y_{k l} \sin \left(\theta_{k l}+\delta_{k}(n, j)-\delta_{l}(n, j)\right) \\
& \quad=0
\end{aligned}
$$

where $P_{g i}(n, j)$ and $Q_{g i}(n, j)$ are the real and reactive power outputs of the $i$ th generator at the $j$ th state of the $n$th stage, respectively, $P_{d k}^{\prime}(n, j)$ and $Q_{d k}^{\prime}(n, j)$ are the real and reactive power demand of node $k$ at the $j$ th state of the $n$th stage after the DLC, respectively. It is assumed that the power factor of node $k$ does not change before and after the DLC. 
In (24), $P_{d k}^{\prime}(n, j)$ can be obtained using (26), shown at the bottom of the page, where $P_{d k}(n)$ is the real power demand of node $k$ at the $n$th stage before DLC, $D L C_{k}(n, j)$ is the DLC capacity of node $k$ at the $j$ th state of the $n$th stage, $P B_{k}(n)$ is the real power demand payback of node $k$ at the $n$th stage.

DLC capacity constraint:

$$
D L C_{k}(n, j) \begin{cases}\geq 0 & K \leq n \leq K+D T \\ =0 & n>K+D T\end{cases}
$$

where $K$ is the DLC starting hour.

Based on the DLC status at previous stages, the employed load pay-back pattern $P B_{k}(n)$ of node $k$ at the $n$th stage is calculated using (28) [9]:

$$
\begin{aligned}
P B_{k}(n)=0.6 \times D L C_{k}(n-1) & +0.3 \times D L C_{k}(n-2) \\
+ & 0.1 \times D L C_{k}(n-3) .
\end{aligned}
$$

The accumulated disconnection time of the $i$ th ACL at the $n$th stage is given in (29), shown at the bottom of the page, where $T$ is the time interval of each stage and $S_{i}(n)$ is the dispatch state of the $i$ th ACL at the $n$th stage. $S_{i}(n)$ is 1 if ACL is connected to the system; otherwise, $S_{i}(n)$ is 0 . The constraint of $S_{i}(n)$ is given in (30):

$$
S_{i}(n)= \begin{cases}1, & \text { if } A T_{i}(n-1)>\max T_{i} \\ 1, & \text { and if }-\min T_{i}<A T_{i}(n-1)<0 \\ 0, & \text { otherwise }\end{cases}
$$

where $\max T_{i}$ and $\min T_{i}$ are the maximum and minimum accumulated disconnected times of the $i$ th ACL, respectively.

The generation, voltage, power line flow and system spinning reserve constraints are same as those in Section II.

To deal with the variation of the on/off control duration of the ACL, DP is utilized to solve the DLC problem. The DLC period is divided into a number of time intervals, each of which is defined as a stage in the DP. In each stage, a state set is given which includes all the possible DLC dispatch states combined with the corresponding energy market clearing state and spinning reserve clearing state. In such a state, the cumulative system operating cost is the minimum.

The forward DP approach is used to determine the optimal DLC scheme. One candidate DLC dispatch state at current stage reaches all the feasible DLC dispatch states at the next stage subject to the physical constraints of the ACL. In those feasible DLC dispatch states, the state with the minimum system operating cost is chosen as the candidate DLC dispatch state at the next stage. To avoid the explosion of the computation dimension, only $m$ candidate DLC dispatch states are chosen at each stage. The selection of the candidate DLC dispatch states is based on the system operating cost. The chosen $m$ DLC dispatch states at each stage are with the smallest $m$ system operating costs.

The flowchart of the solution algorithm is demonstrated in Fig. 2.

The steps of the solution algorithm are described below:

Step 1) Determine the system loads with all possible DLC schemes.

Step 2) Calculate the system energy cost using (1) and system spinning reserve cost using (11) from time 1 to time $K-1$.

Step 3) Determine the $m$ candidate DLC dispatch states at each stage of the period using DP which are with the $m$ smallest system operating costs among all the feasible DLC dispatch states, the DLC time period is from time $K$ to time $K+D T$.

Step 4) Calculate the cumulative system operating costs after DLC period with the $m$ candidate DLC schemes.

Step 5) Determine the optimal DLC scheme with the minimum cumulative system operating cost.

Step 6) Implement the reliability evaluation for the system with and without the optimal DLC scheme to study the reliability improvement of the system.

\section{Simulation Results}

In order to illustrate the impacts of the proposed DLC scheme on the peak load shaving, the system reliability and the system operating cost, the IEEE RTS [18] was studied using the program developed based on MATPOWER [25]. The single line diagram of RTS is shown in Fig. 3.

The DLC is implemented during the peak load periods from 17:00 to 20:00 h. Ten ACLs are connected to different nodes of the system. The nodal NIEAR and ACL capacity of each node are shown in Table I. Each stage of the DP structure is $1 \mathrm{~h}$ and includes 1024 states with different DLC dispatch states.

$$
P_{d k}^{\prime}(n, j)= \begin{cases}P_{d k}(n), & \text { if there is no DLC at node } k \\ P_{d k}(n, j)-D L C_{k}(n, j)+P B_{k}(n), & \text { if there is DLC at node } k\end{cases}
$$

$$
A T_{i}(n)= \begin{cases}A T_{i}(n-1)+T, & \text { if } S_{i}(n-1)=0 \text { and } S_{i}(n)=0 \\ T, & \text { if } S_{i}(n-1)=1 \text { and } S_{i}(n)=0 \\ -T, & \text { if } S_{i}(n-1)=0 \text { and } S_{i}(n)=1 \\ A T_{i}(n-1)-T, & \text { if } S_{i}(n-1)=1 \text { and } S_{i}(n)=1\end{cases}
$$




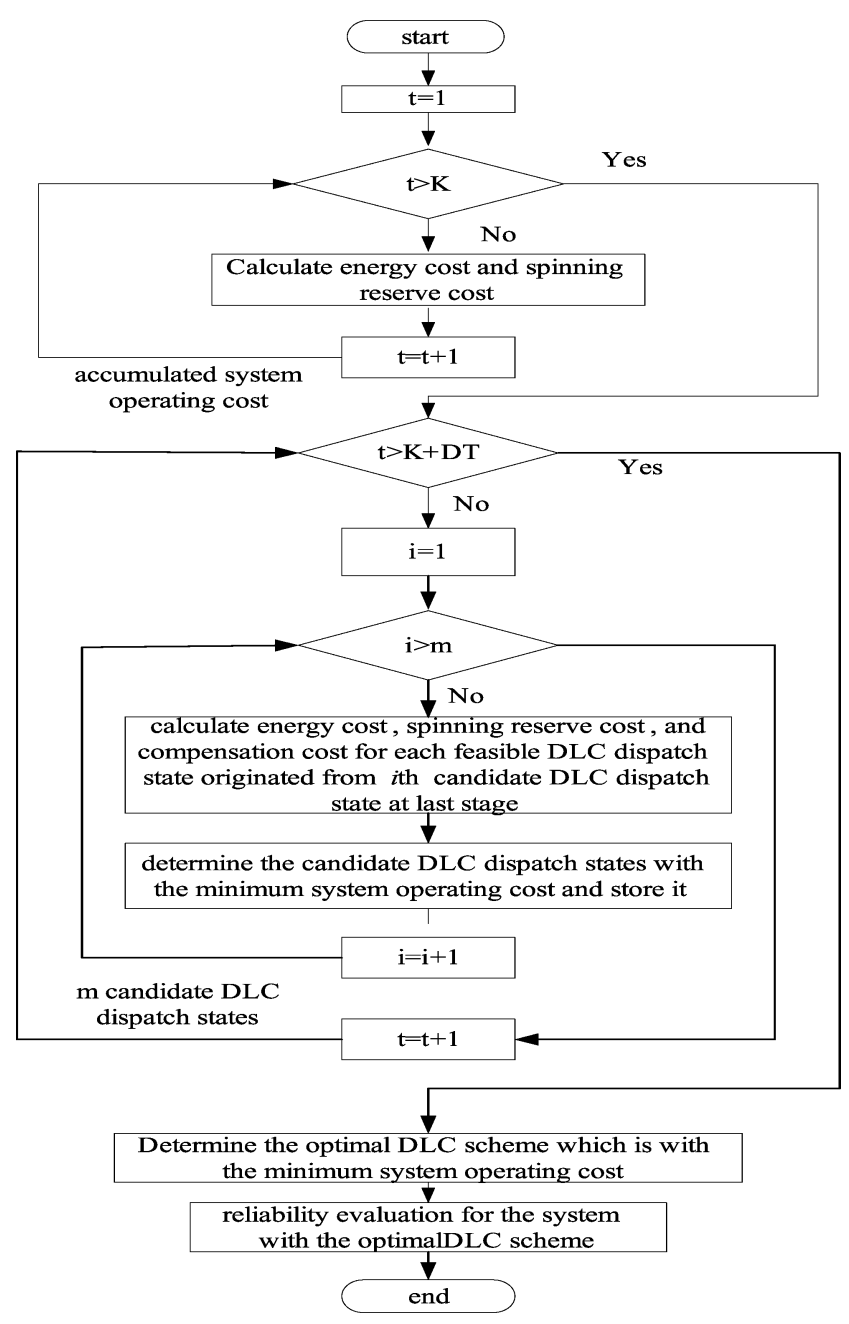

Fig. 2. Flowchart of the solution algorithm.

In order to avoid the explosion of the computation dimension, 100 candidate DLC dispatch states were chosen at each stage.

Two cases were studied to investigate the impact of the proposed DLC scheme of ACL on system operating cost reduction and system reliability improvement. Case 1 is the base case without the DLC. The proposed DLC scheme is implemented in Case 2. The load curves of ACL customers for Cases 1 and 2 are illustrated in Fig. 4.

\section{A. System Operating Cost Analysis}

The system operating costs for the two cases were calculated to demonstrate the system operating cost reduction of the DLC schemes. The energy costs of Cases 1 and 2 are shown in Table II.

With the proposed DLC scheme, the energy cost is reduced from $\$ 431276$ of Case 1 to $\$ 429622$ of Case 2. The reduction of total energy cost is $\$ 3654$ and the percentage change of energy cost is $0.85 \%$.

The spinning reserve costs of Cases 1 and 2 are listed in Table III. The spinning reserve costs of Cases 1 and 2 are $\$ 38505$ and $\$ 37080$, respectively. The reduction of spinning

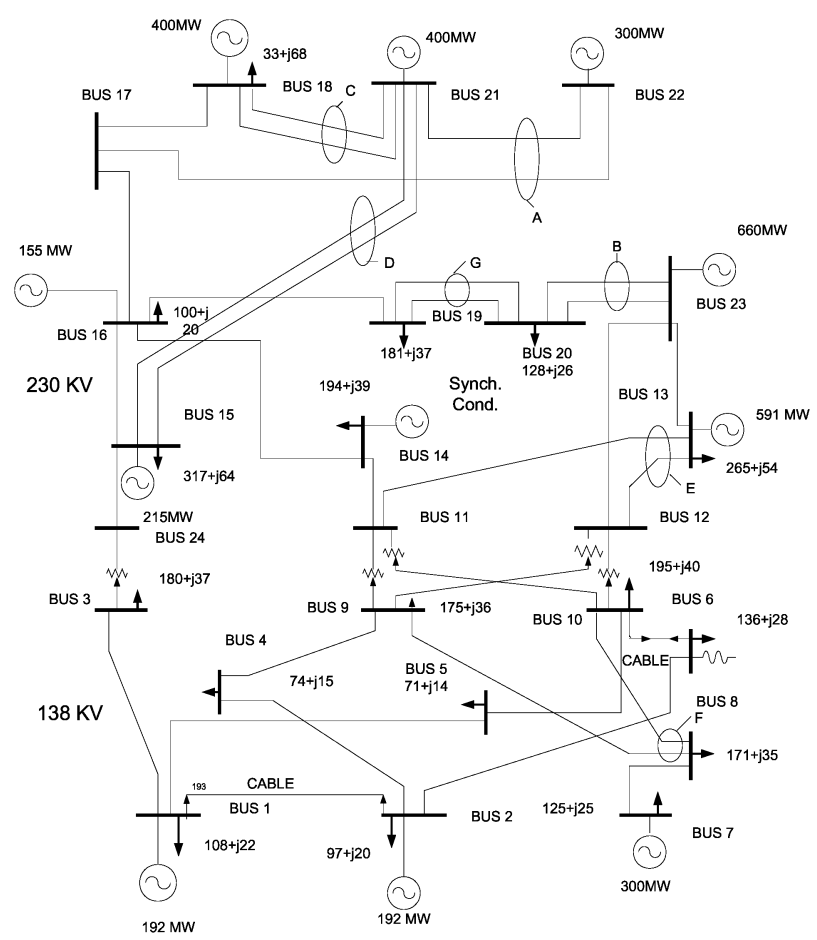

Fig. 3. Single line diagram of the RTS.

TABLE I

NODAL IEAR AND ACL CAPACITY

\begin{tabular}{|c|c|c|c|}
\hline $\begin{array}{c}\text { GROUP } \\
\text { NO. }\end{array}$ & $\begin{array}{c}\text { NODE } \\
\text { NO. }\end{array}$ & $\begin{array}{c}\text { NIEAR } \\
(\text { \$MW })\end{array}$ & $\begin{array}{c}\text { ACL CAPACITY } \\
\text { (MW) }\end{array}$ \\
\hline 1 & 3 & 17.804 & 20 \\
\hline 2 & 4 & 16.966 & 20 \\
\hline 3 & 5 & 17.007 & 20 \\
\hline 4 & 6 & 20.589 & 20 \\
\hline 5 & 7 & 13.332 & 20 \\
\hline 6 & 8 & 10.857 & 20 \\
\hline 7 & 9 & 13.775 & 20 \\
\hline 8 & 10 & 12.542 & 20 \\
\hline 9 & 14 & 16.642 & 20 \\
\hline 10 & 18 & 16.828 & 20 \\
\hline
\end{tabular}

reserve cost is $\$ 4172$. The spinning reserve cost is reduced by $7.4 \%$.

The compensation costs for ACL customers are shown in Table IV. The ACL customers are compensated based on their NIEARs. The compensation for the ACL customer at node 4 is the largest and the compensation for the ACL customers at node 6 is the smallest. The total compensation for the ACL customers is $\$ 6253.7$.

The total system operating costs for Cases 1 and 2 are shown in Table V. The system operating cost is reduced from $\$ 486935$ of Case 1 to $\$ 485404.7$ of Case 2. The reduction of the system operating cost is $\$ 1530.3$ and the percentage change of the system operating cost is $0.31 \%$. Hence the system operating 


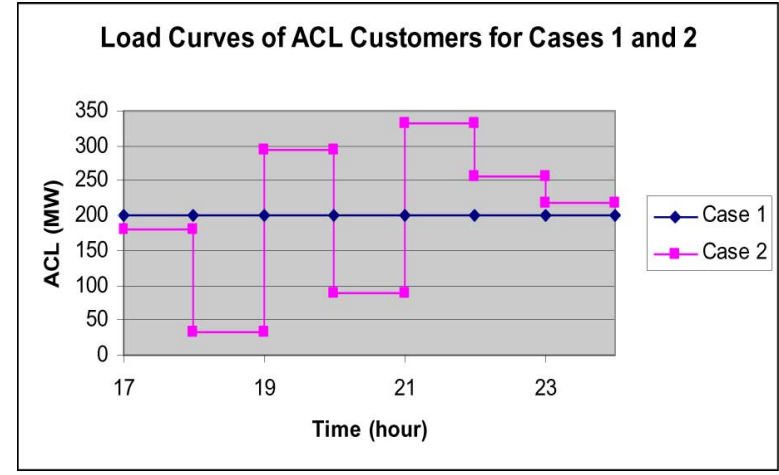

Fig. 4. Load curves of ACL customers for Cases 1 and 2.

TABLE II

ENERGY COSTS OF CASES 1 AND 2

\begin{tabular}{|c|c|c|c|}
\hline & Case 1 & Case 2 & $\begin{array}{c}\text { Change } \\
(\%)\end{array}$ \\
\hline $\begin{array}{c}\text { Energy cost } \\
(\$)\end{array}$ & 431276 & 427622 & 0.85 \\
\hline
\end{tabular}

TABLE III

SPINNING RESERVE COSTS OF CASES 1 AND 2

\begin{tabular}{|l|c|c|c|}
\hline & Case 1 & Case 2 & $\begin{array}{c}\text { Change } \\
(\%)\end{array}$ \\
\hline SR cost (\$) & 55659 & 51532 & 7.4 \\
\hline
\end{tabular}

TABLE IV

COMPENSATION FOR ACL CUSTOMERS

\begin{tabular}{|c|c|c|}
\hline $\begin{array}{c}\text { GROUP } \\
\text { NO. }\end{array}$ & NODE NO. & $\begin{array}{c}\text { COMPENSATION } \\
(\$)\end{array}$ \\
\hline 1 & 3 & 712.1600 \\
\hline 2 & 4 & 678.6400 \\
\hline 3 & 5 & 680.2800 \\
\hline 4 & 6 & 823.5600 \\
\hline 5 & 7 & 533.2800 \\
\hline 6 & 8 & 434.2800 \\
\hline 7 & 9 & 551.0000 \\
\hline 8 & 10 & 501.6800 \\
\hline 9 & 14 & 665.6800 \\
\hline 10 & 18 & 673.1200 \\
\hline
\end{tabular}

TABLE V

SYSTEM OPERATING COSTS OF CASES 1 AND 2

\begin{tabular}{|c|c|c|c|}
\hline & Case 1 & Case 2 & Change (\%) \\
\hline $\begin{array}{c}\text { Operating } \\
\text { cost (\$) }\end{array}$ & 486935 & 485404.7 & 0.67 \\
\hline
\end{tabular}

cost is reduced by implementing the proposed DLC scheme of ACL.
TABLE VI

SYSTEM RELIABILITY INDICES FOR CASES 1AND 2

\begin{tabular}{|c|c|c|c|}
\hline Indices & Case 1 & Case 2 & Change (\%) \\
\hline EENS & 424.81 & 267.94 & 36.93 \\
\hline
\end{tabular}

\section{B. System Reliability Improvement}

The system EENS for Cases 1 and 2 were calculated to analyze the system reliability improvement of the proposed DLC scheme. The system EENS for Cases 1 and 2 are shown in Table VI.

The EENS of the system is reduced from $424.81 \mathrm{MWh}$ of Case 1 to $267.94 \mathrm{MWh}$ of Case 2 and the percentage change is $36.93 \%$. It can be concluded that the proposed DLC scheme can significantly improve the system reliability.

\section{CONCLUSIONS}

A DLC scheme of ACL considering the NIEAR is proposed for restructured power systems in order to encourage the ACL customers to participate in the DLC program and to compensate the ACL customers according to their contribution to the system reliability improvement at the same time. The NIEAR is used to determine the compensation rate to the ACL customers for participating in the DLC program. DP is used to determine the optimal DLC scheme of ACL under the minimum system operating cost.

The IEEE RTS was used to illustrate the proposed DLC scheme. The simulation results with and without the proposed DLC technique show that the developed DLC scheme can improve the system reliability and reduce the system operating cost of restructured power systems. Moreover, the proposed DLC scheme compensates the ACL customers based on the NIEARs. The scheme will be more acceptable to the ACL customers because it is reasonable and fair.

\section{REFERENCES}

[1] K. Bhattacharya, M. H. J. Bollen, and J. E. Daalder, Operation of Restructured Power Systems. Boston, MA: Kluwer, 2001.

[2] M. Shahidehpour and M. Alomoush, Restructured Electrical Power Systems: Operation, Trading and Volatility. New York: Marcel Dekker, 2001.

[3] F. I. Denny and D. E. Dismukes, Power System Operations and Electricity Markets. Boca Raton, FL: CRC, 2002.

[4] Y. Song and X. Wang, Operation of Market-Oriented Power Systems. London, U.K.: Springer, 2006.

[5] G. C. Heffner and C. A. Goldman, "Demand responsive programs-an emerging resource for competitive electricity markets?," in Proc. Int. Energy Program Evaluation Conf., Salt Lake City, UT, Aug. 22-24, 2001.

[6] A. I. Cohen, "An optimization method for load management scheduling," IEEE Trans. Power Syst., vol. 3, no. 2, pp. 612-618, May 1988.

[7] H. Salehfar and A. D. Patton, "Modeling and evaluation of the system reliability effects of direct load control," IEEE Trans. Power Syst., vol. 4, no. 3, pp. 1024-1030, Aug. 1989.

[8] N. E. Ryan, J. T. Powers, S. D. Braithwait, and B. A. Smith, "Generalizing direct load control program analysis: Implementation of the duty cycle approach," IEEE Trans. Power Syst., vol. 4, no. 1, pp. 293-299, Feb. 1989.

[9] H. Salehfar and A. D. Patton, "A production costing methodology for evaluation of direct load control," IEEE Trans. Power Syst., vol. 6, no. 1, pp. 278-284, Feb. 1991. 
[10] J. Chen, F. N. Lee, A. M. Breipohl, and R. Adapa, "Scheduling direct load control to minimize system operational cost," IEEE Trans. Power Syst., vol. 10, no. 4, pp. 1994-2001, Nov. 1995.

[11] K. Bhattacharyya and M. L. Crow, "A fuzzy logic based approach to direct load control," IEEE Trans. Power Syst., vol. 11, no. 2, pp. 708-714, May 1996.

[12] O. Samuelsson and B. Eliasson, "Damping of electro-mechanical oscillations in a multi-machine system by direct load control," IEEE Trans. Power Syst., vol. 12, no. 4, pp. 1604-1609, Nov. 1997.

[13] A. Molina, A. Gabaldon, J. A. Fuentes, and C. Alvarez, "Implementation and assessment of physically based electrical load models: Application to direct load control residential programs," Proc. Inst. Elect. Eng., Gen., Transm., Distrib., vol. 150, no. 1, pp. 61-67, Jan. 2003.

[14] B. Ramanathan and V. Vittal, "A small signal stability performance boundary for direct load control," in Proc. IEEE PES Power Systems Conf. Expo., Oct. 2004, vol. 2, pp. 1078-1083.

[15] B. Ramanathan and V. Vittal, "Small-Disturbance angle stability enhancement through direct load control part I-framework development," IEEE Trans. Power Syst., vol. 21, no. 2, pp. 773-781, May 2006.

[16] B. Ramanathan and V. Vittal, "Small-Disturbance angle stability enhancement through direct load control part II-numerical simulations and results," IEEE Trans. Power Syst., vol. 21, no. 2, pp. 782-790, May 2006.

[17] A. Gomes, C. H. Antunes, and A. G. Martins, "A multiple objective approach to direct load control using an interactive evolutionary algorithm," IEEE Trans. Power Syst., vol. 22, no. 3, pp. 1004-1011, Aug. 2007.

[18] The Reliability Test System Task Force of the Application of Probability Methods Subcommittee, "IEEE reliability test system," IEEE Trans. Power App. Syst., vol. PAS-98, pp. 2047-2054, Nov./Dec. 1979.

[19] R. Billinton, J. Oteng-Adjei, and R. Ghajar, "Comparison of two alternate methods to establish an interrupted energy assessment rate," IEEE Trans. Power Syst., vol. 2, no. 3, pp. 751-757, Aug. 1987.

[20] J. Oteng-Adjei and R. Billinton, "Evaluation of interrupted energy assessment rates in composite systems," IEEE Trans. Power Syst., vol. 5, no. 4, pp. 1317-1323, Nov. 1990.

[21] L. Goel and R. Billinton, "Evaluation of interrupted energy assessment rates in distribution systems," IEEE Trans. Power Del., vol. 6, no. 4, pp. 1876-1882, Oct. 1991.

[22] L. Goel and R. Billinton, "A procedure for evaluating interrupted energy assessment rates in an overall electric power systems," IEEE Trans. Power Syst., vol. 6, no. 4, pp. 1396-1403, Nov. 1991.

[23] G. Wacker and R. Billinton, "Customer cost of electric service interruptions," Proc. IEEE, vol. 77, no. 6, pp. 919-930, Jun. 1989.

[24] R. Billinton and R. N. Allan, Reliability Evaluation of Power Systems. New York: Plenum, 1994.

[25] [Online]. Available: http://www.pserc.cornell.edu/matpower/.

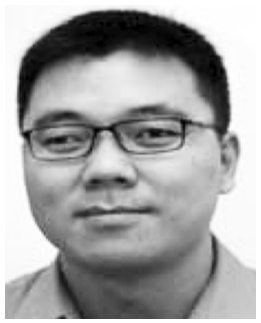

Qiuwei Wu (M'09) received the B.E. and M.E. degrees from Nanjing University of Science and Technology, Nanjing, China, in 2000 and 2003, respectively, both in power system and automation, and the Ph.D. degree in power system engineering from Nanyang Technological University, Singapore, in 2009.

He was working as a Senior R\&D Engineer in Vestas Technology R\&D Singapore Pte. Ltd. from March 2008 to October 2009. Now he is a PostDoc in the Centre for Electric Technology, Technical University of Denmark, Kgs. Lyngby, Denmark. His research interests are reliability improvement and price volatility reduction of restructured power systems using demand response programs, integration study for wind farms, and integration of electrical vehicles to grid for high penetration of wind power.

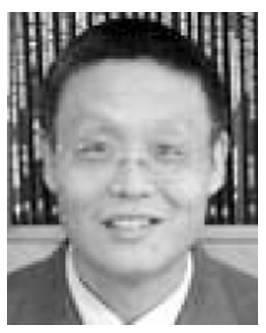

Peng Wang (M'00) received the B.Sc. degree from Xian Jiaotong University, Xian, China, in 1978, the M.Sc. degree from Taiyuan University of Technology, Shanxi, China, in 1987, and the M.Sc. and Ph.D. degrees from the University of Saskatchewan, Saskatoon, SK, Canada, in 1995 and 1998, respectively.

Currently, he is an Associate Professor at Nanyang Technological University, Singapore.

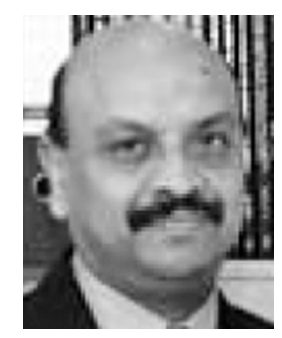

Lalit Goel (SM'95) was born in New Delhi, India, in 1960. He received the B.Tech. degree in electrical engineering from the Regional Engineering College, Warangal, India, in 1983 and the M.Sc. and Ph.D. degrees in electrical engineering from the University of Saskatchewan, Saskatoon, SK, Canada, in 1988 and 1991 respectively.

He joined the School of Electrical and Electronic Engineering at the Nanyang Technological University (NTU), Singapore, in 1991, where he is presently a Professor of division of power engineering and Dean of admissions and financial aid. 